\title{
Promoting Gender Equity at the Journal of Hospital Medicine
}

\author{
Samir S Shah, MD, MSCE ${ }^{1 *}$, Erin E Shaughnessy, MD, MSHCM², Nancy D Spector, MD³
}

'Divisions of Hospital Medicine and Infectious Diseases, Cincinnati Children's Hospital Medical Center, University of Cincinnati College of Medicine, Cincinnati, Ohio; 'Division of Pediatric Hospital Medicine, Children's of Alabama, University of Alabama-Birmingham, Birmingham, Alabama; ${ }^{3}$ Office of Faculty and the Executive Leadership in Academic Medicine Program, Drexel University College of Medicine, Philadelphia, Pennsylvania.

ast year we pledged to lead by example and improve representation within the Journal of Hospital Medicine community. ${ }^{1}$ By emphasizing diversity, we expand the pool of faculty to whom leadership opportunities are available. A diverse team will put forth a broader range of ideas for consideration, spur greater innovation, and promote diversity in both published content and authorship, ensuring that the spectrum of content we publish reflects and benefits all patients to whom we provide care.

We write to share our progress, first reporting on gender equity. Currently, $45 \%$ of the journal leadership team are women, increased from $30 \%$ in 2018. In the past year, we also developed processes to collect peer reviewer and author demographic information through our manuscript management system. These processes helped us understand our baseline state.

Prior to developing these processes, we discussed our goals and potential approaches with Society of Hospital Medicine leaders; medical school deans of diversity, equity, and inclusion; department chairs in pediatrics and internal medicine; women, underrepresented minorities, and LGBTQ+ faculty; and trainees. We achieved consensus as a journal leadership team and implemented a new data collection system in July 2019. We focused on first and last authors given the importance of these positions for promotion and tenure. We requested that peer reviewers and authors provide demographic data, including gender (with nonbinary as an option), race, and ethnicity; "prefer not to answer" was a response option for each question. These data were not available during the manuscript decision process. Authors who did not submit information received up to three reminder emails from the Editor-in-Chief encouraging them to provide demographic information and stating the rationale for the request. We did not use gender identifying algorithms (eg, assignment of gender probability based on name) or visit professional websites; our intent was author self-identification.

We categorized Journal of Hospital Medicine article types as research, generally solicited, and generally unsolicited (Table). Among research articles, the proportion of women and men were similar with women accounting for $47 \%$ of first authors (vs $47 \%$ men) and $33 \%$ of last authors (vs 35\% men) (Table). However, $27 \%$ of last authors left this field blank.

*Corresponding Author: Samir S Shah, MD, MSCE; Email: Samir.Shah@cchmc. org; Telephone: 513-636-6222; Twitter: @SamirShahMD.

Received: August 13, 2020; Accepted: August 13, 2020

๑) 2020 Society of Hospital Medicine DOI 10.12788/jhm.3522
TABLE. Authorship by Gender of Articles Published in JHM Between July 2019 and June 2020a

\begin{tabular}{lccc}
\hline & $\begin{array}{c}\text { Original Research } \\
\text { or Brief Reports }\end{array}$ & $\begin{array}{c}\text { Nonresearch, } \\
\text { Solicited }\end{array}$ & $\begin{array}{c}\text { Nonresearch, } \\
\text { Unsolicited }^{\mathbf{d}}\end{array}$ \\
\hline First Author $^{\mathrm{b}}$ & $\mathbf{N}=\mathbf{6 0}$ & $\mathbf{N}=\mathbf{1 0 8}$ & $\mathbf{N}=\mathbf{2 4}$ \\
\hline Gender & $28(47 \%)$ & $50(46 \%)$ & $13(54 \%)$ \\
Men & $28(47 \%)$ & $50(46 \%)$ & $6(25 \%)$ \\
Women & $2(3 \%)$ & $4(4 \%)$ & $1(4 \%)$ \\
Prefer not to answer & $2(3 \%)$ & $4(4 \%)$ & $4(17 \%)$ \\
Blank & $\mathrm{N}=60$ & $\mathrm{~N}=93$ & $\mathbf{N}=\mathbf{2 2}$ \\
\hline Last Author & & & $6(27 \%)$ \\
\hline Gender & $21(35 \%)$ & $56(60 \%)$ & $6(27 \%)$ \\
Men & $20(33 \%)$ & $18(19 \%)$ & 0 \\
Women & $3(5 \%)$ & $2(2 \%)$ & $10(45 \%)$ \\
Prefer not to answer & $16(27 \%)$ & $17(18 \%)$ & \\
Blank & & &
\end{tabular}

No author selected nonbinary gender.

${ }^{b}$ Articles with only one author were considered to have a first author but no last author to avoid double counting.

'Generally solicited article types include From the Editor-in-Chief (2), Leadership and Professional Development (12), Clinical Guideline Highlights for the Hospitalist (8), Clinical and Methodological Progress Notes (11), Editorials (31), Narrative Reviews (9), and Perspectives in Hospital Medicine (35).

${ }^{d}$ Generally unsolicited article types include Choosing Wisely: Things We Do For No

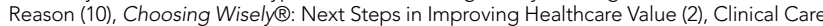
Conundrums (6), Special Announcements (1), Society Position Statements (2), and Letters to the Editor (3)

Among solicited article types, there was an equal proportion of women and men for first but not for last authors. Among unsolicited article types, a smaller proportion of women accounted for first authors. While the proportion of women and men was equal among last authors, $45 \%$ left this field blank.

Collecting author demographics and reporting our data on gender represent an important first step for the journal. In the upcoming year, we will develop strategies to obtain more complete data and report our performance on race, ethnicity, and intersectionality, and continue deliberate efforts to improve equity within all areas of the journal, including reviewer, author, and editorial roles. We are committed to continue sharing our progress.

Disclosures: The authors have no conflicts to disclose.

\section{References}

1. Shah SS, Shaughnessy EE, Spector ND. Leading by example: how medical journals can improve representation in academic medicine. J Hosp Med. 2019;14:393. https://doi.org/10.12788/jhm.3247 